\title{
Cancer: Our Body's Global Warming Warning
}

\author{
Richard M Fleming1*, Matthew R Fleming ${ }^{1}$, Tapan K Chaudhuri², Andrew McKusick ${ }^{1,3}$ and William C Dooley ${ }^{4}$ \\ ${ }^{1}$ FHHI Omnific Imaging Camelot Los Angeles, USA \\ ${ }^{2}$ Eastern Virginia Medical School Norfolk, USA \\ ${ }^{3}$ Sebec Consulting \& Media Rock Hill, USA \\ ${ }^{4}$ Oklahoma University Health Science Center Oklahoma City, USA
}

*Corresponding author: Richard M. Fleming, FHHI Omnific Imaging Camelot Los Angeles, CA, USA

\section{Opinion}

Monday 4 February 2019 was yet another World Cancer Day. We celebrated our efforts to find and eradicate cancer without admitting to ourselves that cancer isn't a single disease, but rather a group of diseases all caused by our bodies responding to the toxic environment we are exposing ourselves to, just as our planet is responding to the toxic wastes we are dumping into it. The question is WHY do our bodies run amok. The answer lies in the same answer to why Global Warming exists. It is the untold unimaginable continued damage and destruction we cause to the world and to ourselves that accounts for the destruction of the planet and the development of cancer within us. While some individuals may have a genetic predisposition [1] for certain types of cancers, it is nonetheless this constant bombarding of ourselves with toxins, which our bodies try to react to and when overwhelmed the climate change of our bodies occur and call for the eradication of first the damaged cells and then eventually ourselves. Just as the continued bombardment of our Earth with environmental toxins is resulting in violent changes on the planet in an attempt to respond to and eradicate the cause of the toxins to the plant, so too are our bodies reacting to try to eradicate these toxins and their effect within our bodies. This process on a biological basis is reflected in how the cells of our body respond to the cellular environment as shown in Figure1. The process of developing cancer or not developing cancer is not a sudden change but rather a transitional series of events resulting from the interaction between the specific responses and expression of the genome of the cell involved and the specific environment in which the cell is immersed. This environment includes both carcinogenic and non-carcinogenic factors. As the insults occur, the cellular mechanisms to respond to those insults include a variety of responses, including cellular repair and immunologic reactions. The outcome is determined by the interaction between these two opposing sets of factors. Progression or regression is determined by these responses. Clearly no one wants to have cancer or for the planet to be destroyed. Confusion comes from not knowing what is helpful and what is hurting us. Until recently [2], we have been limited by testing (qualitative imaging, biomarkers, etc.), which at best can only provide a yes/no answer to the question of whether a person has cancer or not. Many of these tests do not even provide a yes/no answer, but rather infer there could be a problem. These qualitative approaches are unable to provide us with information warning us that these transitional changes are happening [3]; changes which we could act upon if we only knew they were occurring. Changes which when measured could be used to determine if a given treatment is working [4], harming us or having no effect. Measurable changes which can show us cancer in its early stages [5]. These transitional changes can now be measured using FMTVDM [2]. The only question is whether we use this tool to help find these transitional changes and guide our treatment regimens or whether we will continue to pretend that what we are doing is working? 


\section{Quantification of the Changes in "Health-Spectrum"}

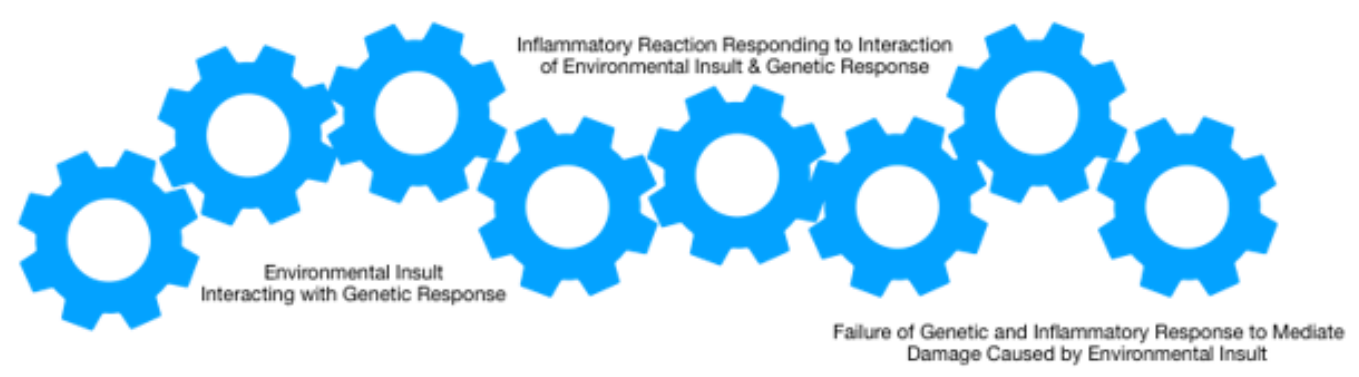

Absence of

Death from Disease

Disease

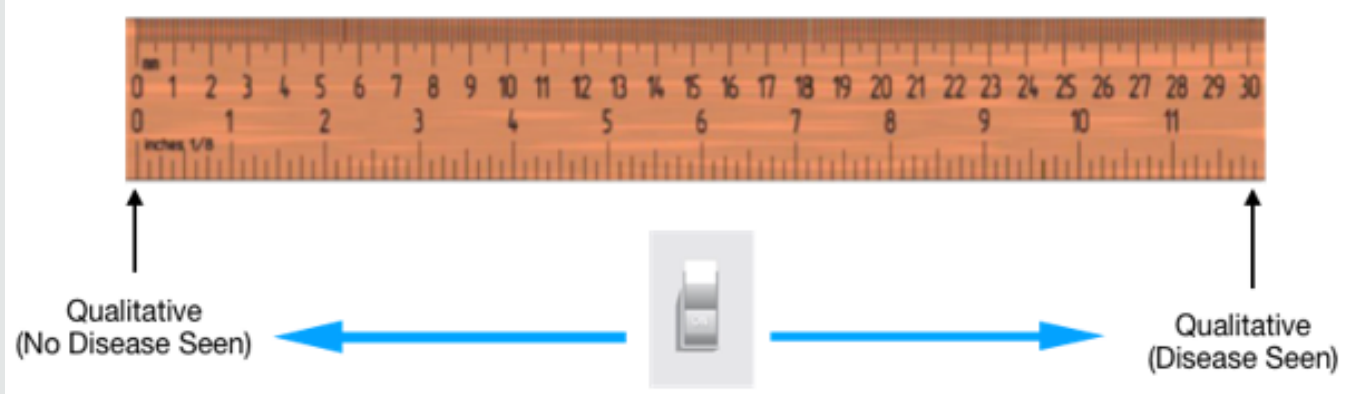

Figure 1: Quantification of the "Health-Spectrum" for Cancer.

\section{References}

1. Fleming RM, Fleming MR, Dooley WC, McKusick A (2018) FMTVDMBEST(C) (P) Breast Cancer Imaging eliminates the fear of having BRCA1 and BRCA2 Breast Cancer Genes. J Clin Mol Med 1(2): 1-2.

2. (2017) The Fleming Method for Tissue and Vascular Differentiation and Metabolism (FMTVDM) using same state single or sequential quantification comparisons. Patent Number 9566037.

3. Miller AB, Wall C, Baines CJ, Ping Sun, Teresa T, et al. (2014) Twenty-fiveyear follow-up for breast cancer incidence and mortality of the Canadian
National Breast Screening Study: randomized screening trial. BMJ 11: 348: 366.

4. Fleming RM, Fleming MR, Chaudhuri TK, Dooley WC (2019) Theranostic Information Provided by FMTVDM(C)(D; BEST (C) (P) Imaging. Adv Hema Onco Res 2(1): 1-3.

5. Fleming RM, Fleming MR, Chaudhuri TK, Dooley WC, McKusick A (2019) Unmasking Hidden Recurrent Cancers using FMTVDM/BEST. The Fleming Cancer Hypothesis. Int J Women's Health Wellness 5(2): 94.

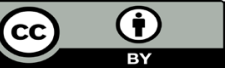

This work is licensed under Creative Commons Attribution 4.0 License

To Submit Your Article Click Here:

Submit Article

DOI: 10.32474/OAJOM.2019.03.000154

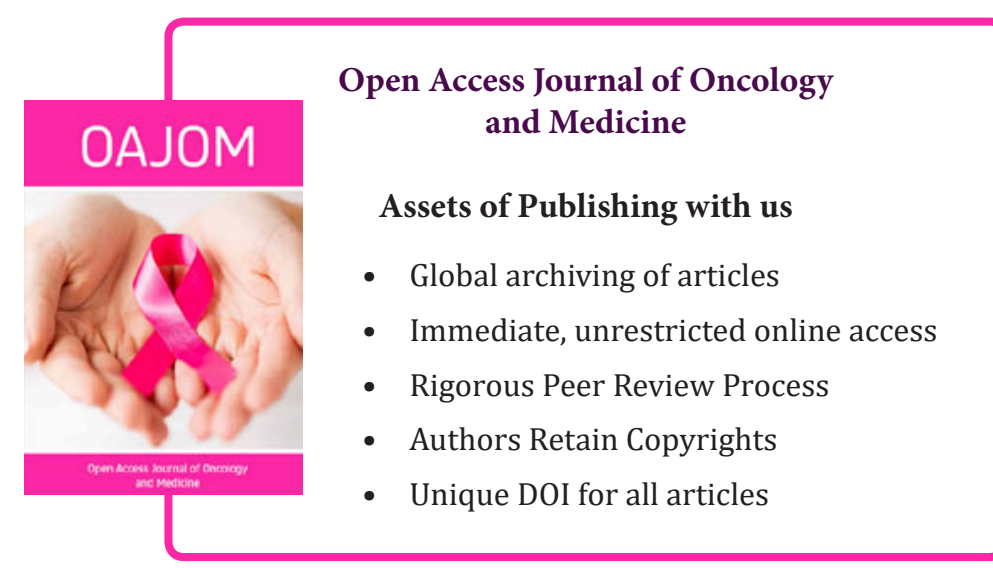

